\title{
The Influence of Ifn $\gamma$ and IL-17A on the Severity of Thyroid Gland Inflammation in Iraqi Patients with Autoimmune Thyroiditis
}

\author{
Ali Majid Al-Jibory', Montaha A.Al-Saffar ${ }^{2}$ and Issam AL-Ani ${ }^{3}$ \\ ${ }^{1,3}$ Middle Technical university-College of Health and Medical Technologies-Baghdad-Iraq \\ ${ }^{2}$ Middle Technical university,Department of community health, Institute of Medical \\ Technology, Baghdad, Iraq. \\ Corresponding author email: ali.majid1990.aa@gmail.com
}

\section{ABSTRACT}

Introduction:Autoimmune thyroid diseases is one of the most diseases which have an influence on the degree thyroid gland inflammation in patients that suffer from thyroid gland autoimmunity. one of diseasfeture is that lead to inflammotry cytokines, this study has been focused in this type of diseas which includeIFN $\gamma$ and IL-17 as well as TSH and T3 hormones. Ninty (90) blood samples were collected from patients suffering thyroid gland disease in both gender whose age ranged 15-65 years, for the period from September to the end of November 2021 from Baghdad teaching hospitals, samples divided into 60 patients groups and 30 healthy control. All samples were tested to evaluate the levels of TSH and T3 hormones, IFN $\gamma$ and IL-17A cytokines by using the ELISA technique. Patients groups were divided into autoimmune hyperthyroidism and autoimmune hypothyroidism, and the highest frequency was in age range (15-44) years at $76.00 \%$ and $63.16 \%$ respectively and thefemales frequency about $19(76.00 \%)$ more than males $6(24.00 \%)$ in autoimmune hyperthyroidism. Our results showed non-significant differences at the level of TSH and highly significant differences at the level of T3 hormones in autoimmune hyperthyroidism with a P-value $(\mathrm{p}<0.01)$, while the autoimmune hypothyroidism revealed opposite results. To search for potential immune markers for diagnosis assessment, our results indicate that the major mean value of immunological markers was IL-17 (75.08 \pm 42.19 ), followed by IFN-Gamma (49.69 \pm 21.47 ), while the less Mean value of immunological markers was in Anti -ds DNA, so the result revealed a strong correlation between the selected markers(IL-17), Our result leads to conclude that these markers are one of the main auto-inflammation cytokines in patients with autoimmune thyroiditis.So, the main objectives of this study are linked betweemimmunological indicatorssuch asIL-17A and IFN gamma and affective thyroiditis , Patients with autoimmune thyroiditis have a substantial hormonal imbalance.

\section{KEY WORDS: TSH, T3, IFNT, IL-17A, AUTOIMMUNE THYROIDITIS, THYROID INFLAMMATORY CYTOKINES}

\section{INTRODUCTION}

"Thyroid hormone was produced by the thyroid gland and is responsible for regulating metabolism, development, and a variety of other bodily functions. Thyroid gland, anterior pituitary gland, and hypothalamus comprise a

Biosc Biotech Res Comm P-ISSN: 0974-6455 E-ISSN: 2321-4007

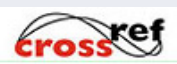

Identifiers and Pagination

Year: 2021 Vol: 14 No (7) Special Issue

Pages: $247-251$

This is an open access article under Creative

Commons License Attribn 4.0 Intl (CC-BY). DOI: $h t t p: / / d x . d o i . o r g / 10.21786 / b b r c / 14.7 .55$ self-regulatory circuit called the hypothalamic-pituitarythyroid axis. Thyroxine (T4) and triiodothyronine (T3) are the main hormones released by the thyroid gland, while Thyrotropin-releasing hormone (TRH) produced from the hypothalamus, thyroid-stimulating hormone (TSH) from the anterior pituitary gland, and T4 work in synchronous harmony to maintain proper feedback mechanism and homeostasis" (A. Antonelli et. al. (2015)).

"The most common reasons of hypothyroidism and hyperthyroidism due to autoimmunity, there were many types of autoimmune thyroid disorders like Graves' disease (GD) and Hashimoto thyroiditis (HT), they were autoimmune thyroid disorders (AITDs),
Article Information

Received: $15^{\text {th }}$ May 2021 ccepted after revision: $20^{\text {th }}$ July 2021 
which has been marked by a loss of self-tolerance to thyroid antigens, leading in antibody circulation and lymphocyte infiltration" (Tagoe et. al. (2015)). "Other types of autoimmune thyroiditis postpartum thyroiditis, painless thyroiditis, and drug-induced thyroiditis. Also, It can be acute, sub-acute, and chronic thyroiditis" (S. Santhoshkumar et. al. (2021)).

The prevalence of HDwas increased, and it was presently believed to affect between 5 and 10\% of the population. It was diagnosed five to ten times more frequently in women than in males, and its prevalence increases with age (the maximum number of cases were seen between the ages of 45 and 65). Cell-mediated autoimmune illness causes HT, while humoral autoimmunity causes GD. (Rydzewska et. al. (2018)). Postpartum thyroiditis PPT was a common endocrine disorder that develops within a year of delivery and affects between 5\% and 10\% of women in the general population (Quandt et. al. (2020)), also was a biphasic condition that begins with temporary thyrotoxicosis (median onset 12-14 weeks postpartum) and ends with transitory hypothyroidism (median onset 18-20 weeks postpartum). (Rich et. al. (2019)). Thyroid hormones influence both innate and adaptive immune responses via genetic and nongenomic pathways. L-thyroxine (T4) and 3,3',5-triiodo-L-thyroxine (T3), which are also components of the "cytokine storm," increase the generation and release of cytokines. (Scappaticcio et. al. (2020)). So , the aim of this study to determined the correlation of the immunological parameters with autoimmune thyroid diseases and identify the specific markers that related to autoimmune thyroiditis among Iraqi,spatients.

Objectives of the study: Our study focused on the following :Determining the correlation of the immunological parameters with autoimmune thyroid diseases (AITD), identification of the hormonal changes in autoimmune thyroiditis Iraqi patients, and demonstrate the significant degree of the pro-inflammatory cytokines in autoimmune thyroiditis patients.

Patients and methods: The current included a collection of ninty (90) blood samples divided into sixty patients groups whose suffereing from thyroid gland diseasesand thirty control group in both gender whose aged 1565 years for the period from September.to the end of November 2021 from educational Laboratories / Baghdad teaching hospital .Serum centrifuged at 3000xg for 30 min and stored at $\left(-20\right.$ to $\left.-80{ }^{\circ} \mathrm{C}\right)$ until analysis.During the sample collection, a questionnaire has been collected by patients that include: Sex, age, family and relative history, smoking, radiation exposure, sera of all 90 sample were analyzed by the ELISA technique to detect the concentrations of the immunological markers IFN $\gamma$ ELISA kitand IL-17 or IL-17A ELISA Kit,according to manufacturer,s instructions (Cusabio Biotech Co. China) and biochemical markers (TSH ELISA Kit, Cusabio biotech Co. China and T3 ELISA Kit, Co. USA hormones). The Thyroid Function Test profile (T3, TSH) and IFN $\gamma$, and IL-17A were performed using ELISA, Human Co.LTD. Germany.

\begin{tabular}{|c|c|c|c|c|c|c|}
\hline \multirow[t]{2}{*}{ Patients group } & \multicolumn{3}{|c|}{ Age(Years) } & \multicolumn{3}{|l|}{ Sex } \\
\hline & No. & $(15-44)$ & $(45-65)$ & No. & Male & Female \\
\hline $\begin{array}{l}\text { Autoimmune } \\
\text { hyperthyroidism }\end{array}$ & \begin{tabular}{|l|}
25 \\
$62.5 \%$
\end{tabular} & $\begin{array}{l}19 \\
(76.00 \%)\end{array}$ & $\begin{array}{l}6 \\
(24.00 \%) \\
\end{array}$ & 25 & $\begin{array}{l}6 \\
(24.00 \%)\end{array}$ & $\begin{array}{l}19 \\
(76.00 \%)\end{array}$ \\
\hline $\begin{array}{l}\text { Autoimmune } \\
\text { hypothyroidism }\end{array}$ & \begin{tabular}{|l|}
19 \\
$47.5 \%$ \\
\end{tabular} & $\begin{array}{l}12 \\
(63.16 \%)\end{array}$ & $\begin{array}{l}7 \\
(36.84 \%) \\
\end{array}$ & 19 & $\begin{array}{l}4 \\
(21.05 \%)\end{array}$ & $\begin{array}{l}15 \\
(78.95 \%)\end{array}$ \\
\hline Total & 44 & $31(70.45 \%)$ & \begin{tabular}{|l|}
13 \\
$(29.55 \%)$ \\
\end{tabular} & 44 & $\begin{array}{l}10 \\
(22.73 \%) \\
\end{array}$ & \begin{tabular}{|l|}
34 \\
$(77.27 \%)$ \\
\end{tabular} \\
\hline P-value & -- & $0.0037 * *$ & & -- & $0.0084 * *$ & \\
\hline
\end{tabular}

Statistical analysis: The data obtained were subjected to analysis by using statistical package of social science (SPSS) version 26.0. Results were expressed as mean standard error and values of $p>0.05$ were considered statically non-significant. While $\mathrm{p} \mathrm{p}<0.05$ and $<0.01$, 0.001 , were considered significantly different and highly significantly different respectively.

\section{RESULT AND DISCUSSION}

In this study, patients have been classified into two groups autoimmune hyperthyroidism and autoimmune hypothyroidism at 25(56.8\%) and 19(43.2\%) respectively , as shown in Table (1). For the current work it is sufficient to put out that the percentage rate of incidence was in age range (15-44) years more than age range (4565) years in both autoimmune hyperthyroidism and autoimmune hypothyroidism at 19(76\%) and 12(63.16\%) respectively. As noted in our results in Table (1) by analyzing according gender of distribution, the result of studied groups according to gender pointed the majority of autoimmune hyperthyroidism were females at 19(76\%) while the frequency of males at $6(24 \%)$ and that mean that the females represent about $77.27 \%$ of the studied 
group. There were highly significant differences among thepatients ages and sex of these groups were $(p \leq 0.01)$.

Biochemical markers: All samples of study groups were estimated for serum TSH and T3 levels by ELISA technique The study results illustrate the comparison between patients groups (autoimmune hyperthyroidism and autoimmune hypothyroidism) and healthy control group among biochemical markers (TSH \& T3). Results in the Table (2) showed a non-significant difference at the level of TSH with $\mathrm{P}$-value $(\mathrm{P}=0.276)$ and significant differences at the level of $\mathrm{T} 3$ hormones in the autoimmune hyperthyroidism patients group compared with the control group With $\mathrm{P}$ value $(\mathrm{p}<0.05)$, while the second patient's group (autoimmune hypothyroidism) in the Table (2) revealed opposite results of the first patient's group (autoimmune hyperthyroidism) which shows significant differences at the level of TSH with $\mathrm{P}$ value $(p<0.05)$ and non-significant difference at the level of T3 hormones compared with the control group. Also, the analysis of the data revealed a significant difference between the autoimmune hyperthyroidism and autoimmune hypothyroidism at the level of TSH while a non-significant differences the autoimmune hyperthyroidism and autoimmune hypothyroidism at the level of T3.

Table 2. Mean value of serum thyroid stimulating hormone (TSH) and triiodothyronine (T3) levels in autoimmune thyroiditis group.

\begin{tabular}{|c|c|c|c|c|}
\hline \multirow[t]{3}{*}{ * Patients group } & \multicolumn{4}{|c|}{ Mean \pm SDof TSH and T3 Hormones } \\
\hline & \multicolumn{2}{|l|}{ TSH } & \multicolumn{2}{|l|}{ T3 } \\
\hline & Mean \pm SD & $\begin{array}{l}\text { P-Value } \\
\text { (With Control) }\end{array}$ & Mean \pm SD & \begin{tabular}{|l|} 
P-Value \\
(With Control)
\end{tabular} \\
\hline Healthy control group & $1.17 \pm 1.04$ & & $2.98 \pm 2.20$ & \\
\hline $\begin{array}{l}\text { Autoimmune } \\
\text { hyperthyroidism }\end{array}$ & $2.36 \pm 1.38$ & $\mathrm{P}=0.276 \mathrm{NS}$ & $2.65 \pm 1.33$ & $\mathrm{P}=0.0007^{* *}$ \\
\hline $\begin{array}{l}\text { Autoimmune } \\
\text { hypothyroidism }\end{array}$ & $5.06 \pm 5.48$ & $\mathrm{P}=0.0002 * *$ & $2.09 \pm 0.65$ & $\mathrm{P}=0.062 \mathrm{NS}$ \\
\hline P-Value (Patients group) & $\mathrm{P}=0.042^{*}$ & & $\mathrm{P}=0.073 \mathrm{NS}$ & \\
\hline
\end{tabular}

Table 3. Comparison between autoimmune thyroiditis patients group and healthy control group according to test results (IL-17 and IFN-Gamma).

\begin{tabular}{|l|l|l|l|}
\hline Parameters & Groups & Mean \pm SD & P-Value \\
\hline \multirow{2}{*}{ IL-17 } & Autoimmune Thyroiditis & $75.08 \pm 42.19$ & \multirow{2}{*}{$0.0001 * *$} \\
\cline { 2 - 3 } & Control & $22.68 \pm 18.55$ & \\
\hline \multirow{2}{*}{ IFN-Gamma } & Autoimmune Thyroiditis & $49.69 \pm 21.47$ & \multirow{2}{*}{$0.0429 *$} \\
\cline { 2 - 3 } & Control & $38.68 \pm 21.46$ & \\
\hline \multirow{2}{*}{$*(\mathrm{P} \leq 0.05)$ - Significant, ** $(\mathrm{P} \leq 0.01)$-Highly Significant. } & \\
\hline
\end{tabular}

2. Inflammatory immunological markers: In the present work, patients with autoimmune thyroiditis were studied in the search for potential immunological markers for diagnosis assessment ,see Table (3). Sera of all study groups were estimated for serum IL-17 and IFN-Gamm, the results from Table (3) revealed the correlation between immunological markers and patients group Our results indicate that immunological parameters (IL-17 and IFN-Gamma) levelsWhen compared with healthy control group, the levels of antibodies in patients with autoimmune thyroiditis are higher, and the major Mean value of immunological markers was
IL-17 (75.08 \pm 42.19$)$ monitored in studied group.while the less Mean value of immunological markers in was

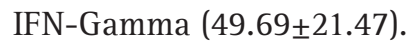

\section{DISCUSSION}

Our result showed a higher frequency of autoimmune hyperthyroidism, moreover our result disagree with the result of (Calcaterra et. al. (2020)) they had found that out of 382 patients with AITD, 361 patients have autoimmune hypothyroidism and 21 patients have autoimmune hyperthyroidism. Our finding revealed the 
risk increased with age, our result regarding the age were agreed with [8], they claimed that the risk of AITD is increased with age also the most affected age group is the young patients group starting under 20 years old. Our sex catogarizaion result agree with (Hasan et. al. (2019)) which have reported that the result revealed female gender has categorically significantly high percentage of occurrence of thyroid abnormality as compared to male gender (75.8\% (females) vs. 24.2\% (males)). Also the highest percentage of participants $(81.9 \%)$ aged between 15-44 years.

In autoimmune hyperthyroidism group the result was an elevation of T3, this occurred due overt activity of thyroid gland which result in high concentration of T3 hormone that influencing the concentration of TSH hormone, these result agreed with the results found by (Ali et. al. (2013)) "conducted on 30 patients from the Iraqi female patients with hyperthyroidism attending Baghdad teaching hospital", also agrees with (Tribulova et. al. (2020)) which has stated that the lower serum TSH levels $(<0.10 \mathrm{mlU} / \mathrm{L})$, while the T3 concentrations are higher than the reference range.

in autoimmune hypothyroidism group shows an increased level of TSH and decreased level of T3 hormones, that is the result of reduced activity of thyroid gland which lead to reduced concentration of T3 that influence and increase concentration of TSH hormones this result is agreed with a study conducted in Duhok province by (Tribulova et. al. (2020)) which have reported, results shows mean TSH serum levels of 25.87 (uIU/ml) for the patients which greatly surpass that of the control group 3.55 (uIU/ml) and it was statistically significantly different $(p<0.001)$. While T3 mean serum levels of 2.04 (nmol/l), 1.5 (nmol/l). Our result also agree with a results by (Metwalley et. al. (2014)) conducted on 94 AITDs Egyptian patients and their finding was that the mean TSH levels were significantly higher when compared to control $(\mathrm{P}<0.01)$. Elevated levels of IFN- $\gamma$ produced by the thyroid infiltrating lymphocytes have been shown to facilitate apoptosis of thyroid follicular cells through caspase activation (Wang et. al. (2007)) Also the result of (Hanv (2019)) agreed with the current study result of IL-17A, there finding was that elevated IL-17A and MHC class I expression were observed in papillary thyroid cancer tissue samples with coexistent HT, but disagree with finding of IFN gamma, they reported a decreased IFN- $\gamma$ secretion.

The present study result of IL-17Ais agreed with that of (Ramos-Levi et. al. (2016)). An elevated levels of cytokines is due to the auto-inflammation and the release of pro-inflammatory mediators from the immune cells to attack own thyrocytes also the stimulation and production of inflammatory mediators that attacks the thyroid gland this result is agreed with that of (Zake (2018), Mele (2020), Miko囚 (2014)). Also Esfahanian, 2017 demonstrated that Hashimoto's thyroiditis is caused by CD4+ T-cells, which play an important role in the disease's pathogenesis (HT). as well as the information on the characteristics and function of newly produced interleukin (IL)-17-producing T-helper cells in this common autoimmune thyroid disorder is limitedThe serum levels of IL-17 were significantly higher in patients ,while no differences were observed with regard to levels of IL-22 and IL-23 between patients and normal controls. These findings imply that IL-17 may have a role in the development of HT (19).

\section{CONCLUSION}

From the revealed data we can draw the following conclusions, the highest concentration of the IL-17A and IFN gamma the more severe inflammation of the thyroid gland in autoimmune thyroiditis. The immunological markers are highly correlated to autoimmune thyroiditis. There is a significant hormonal imbalance among autoimmune thyroiditis patients.

Conflict interest: There is no conflict of interest.

\section{ACKNOWLEDGEMENTS}

We would like to express my special thanks to the members of the sampling collection team at the national center for educational laboratories at Baghdad teaching hospital, who gave me support and help .

\section{REFERENCES}

Ali, B.H., 2013. Evaluation of the new marker interleukin33 in Iraqi female patients with hyperthyroidism. Journal of the Faculty of Medicine Baghdad, 55(2), pp.170-174.

Calcaterra, V., Nappi, R.E., Regalbuto, C., De Silvestri, A., Incardona, A., Amariti, R., Bassanese, F., Clemente, A.M., Vinci, F., Albertini, R. and Larizza, D., 2020. Gender differences at the onset of autoimmune thyroid diseases in children and adolescents. Frontiers in endocrinology, 11, p.229.

Esfahanian, F., Ghelich, R., Rashidian, H. and Jadali, Z., 2017. Increased levels of serum interleukin-17 in patients with Hashimoto's thyroiditis. Indian journal of endocrinology and metabolism, 21(4), p.551.

Ezhilarasi, G.D., Latchoumi, T.P. and Balamurugan, K., 2020. UIP-A Smart Web Application to Manage Network Environments, Advances in Intelligent systems and computing book series.

Ferri, C., Colaci, M., Fallahi, P., Ferrari, S.M., Antonelli, A. and Giuggioli, D., 2017. Thyroid involvement in hepatitis C virus-infected patients with/without mixed cryoglobulinemia. Frontiers in endocrinology, 8, p.159.

Han, L.T., Hu, J.Q., Ma, B., Wen, D., Zhang, T.T., Lu, Z.W., Wei, W.J., Wang, Y.L., Yu, W.A.N.G., Liao, T. and Ji, Q.H., 2019. IL-17A increases MHC class I expression and promotes $\mathrm{T}$ cell activation in papillary thyroid cancer patients with coexistent Hashimoto's thyroiditis. Diagnostic pathology, 14(1), pp.1-10.

Hasan, R.I. and Raziq, A.H., 2019. Studying the Frequency of Autoimmune Thyroid Diseases in Duhok 
Province. Science Journal of University of Zakho, 7(2), pp.45-49.

Martin, T.C., Illieva, K.M., Visconti, A., Beaumont, M., Kiddle, S.J., Dobson, R.J., Mangino, M., Lim, E.M., Pezer, M., Steves, C.J. and Bell, J.T., 2019. Multi-omic analyses reveal antibody-dependent natural killer cell-mediated cytotoxicity in autoimmune thyroid diseases. bioRxiv, p.662957.

Mele, C., Caputo, M., Bisceglia, A., Samà, M.T., Zavattaro, M., Aimaretti, G., Pagano, L., Prodam, F. and Marzullo, P., 2020. Immunomodulatory effects of vitamin D in thyroid diseases. Nutrients, 12(5), p.1444.

Metwalley, K.A. and El-Saied, A.R.A.H., 2014. Thyroid abnormalities in Egyptian children and adolescents with type 1 diabetes mellitus: a single center study from Upper Egypt. Indian journal of endocrinology and metabolism, 18(5), p.637.

Mikos, H., Mikos, M., Obara-Moszynska, M. and Niedziela, M., 2014. The role of the immune system and cytokines involved in the pathogenesis of autoimmune thyroid disease (AITD). Endokrynologia Polska, 65(2), pp.150-155.

Mishra, P., Jimmy, L., Ogunmola, G.A., Phu, T.V., Jayanthiladevi, A. and Latchoumi, T.P., 2020, December. Hydroponics cultivation using real time iot measurement system. In Journal of Physics: Conference Series (Vol. 1712, No. 1, p. 012040). IOP Publishing.

Prasath, S. (2020). Probabilistic Mceliece Public-Key Cryptography Based Identity Authentication For Secured Communication In Vanet. Solid State Technology, 63(6), 10167-10182.

Prasath, S. Validating Data Integrity in Steganographed Images using Embedded Checksum Technique. International Journal of Computer Applications, 975, 8887.

Quandt, Z.E., Salmeen, K.E. and Block-Kurbisch, I.J., 2020. Thyroid Disorders During Pregnancy, Postpartum, and Lactation. Maternal-fetal and neonatal endocrinology, pp.287-315.

Ramos-Leví, A.M. and Marazuela, M., 2016. Pathogenesis of thyroid autoimmune disease: the role of cellular mechanisms. Endocrinología y Nutrición, 63(8), pp.421429.

Rich, R.R. and Chaplin, D.D., 2019. The human immune response. In Clinical Immunology (pp. 3-17). Elsevier. Santhoshkumar, S., Ramasamy, U., Mansuour, R.F. and Ramaraj, E., 2021, January. A Review on Statistical Importance and Biomarkers Identification in Hashimoto Thyroiditis Disease. In 2021 11th International Conference on Cloud Computing, Data Science \& Engineering (Confluence) (pp. 1040-1045). IEEE.

Scappaticcio, L., Pitoia, F., Esposito, K., Piccardo, A. and Trimboli, P., 2020. Impact of COVID-19 on the thyroid gland: an update. Reviews in endocrine and metabolic disorders, pp.1-13.

Tagoe, C.E., Sheth, T., Golub, E. and Sorensen, K., 2019. Rheumatic associations of autoimmune thyroid disease: a systematic review. Clinical rheumatology, 38(7), pp.1801-1809.

Tribulova, N., Kurahara, L.H., Hlivak, P., Hirano, K. and Szeiffova Bacova, B., 2020. Pro-arrhythmic signaling of thyroid hormones and its relevance in subclinical hyperthyroidism. International journal of molecular sciences, 21(8), p.2844.

Venkata Pavan, M., Karnan, B. and Latchoumi, T.P., 2021. PLA-Cu reinforced composite filament: Preparation and flexural property printed at different machining conditions. Advanced Composite Materials, https://doi. org/10.1080/09243046.2021, 1918608.

Wang, S.H. and Baker Jr, J.R., 2007. The role of apoptosis in thyroid autoimmunity. Thyroid, 17(10), pp.975979.

Zake, T., Skuja, S., Kalere, I., Konrade, I. and Groma, V., 2018. Heterogeneity of tissue IL-17 and tight junction proteins expression demonstrated in patients with autoimmune thyroid diseases. Medicine, 97(25). 